\title{
ORGANIZATIONAL DOWNSIZING
}

\author{
by \\ Hyun-gu Kang
}

A Research Paper

Submitted in Partial Fulfillment of the

Requirements for the

Master of Science Degree in

Management Technology

Approved for Completion of 3 Semester Credits

(150-780 Course Title)

Research Advisor

The Graduate College

University of Wisconsin-Stout

May, 1999 
The Graduate College

University of Wisconsin-Stout

Menomomie, Wisconsin 54751

\section{ABSTRACT}

$\begin{array}{clc}\text { Kang } & \text { Hyun-gu } & \\ (\text { Writer }) & \text { (Last Name) } & \text { (First) }\end{array}$

Organizational Downsizing

(Title)

Management Technology Dr. Wallace C. Carlson May/1999 42

(Graduate Major) (Research Adviser) (Month/Year) (No. of Pages)

Although reports of job losses due to corporate restructuring are commonplace, close examination reveals that downsizing may not be the solution. According to Statistics America, more than 1 million people are displaced annually in permanent layoffs in America, many of them ending up self-employed, which often results in a lower income. Moreover, at least 50 percent of downsizing efforts fail to meet financial objectives due to poor planning, leadership, and communication, according to Professor Ronald Burke of the Schulich School of Business at Toronto's York University.

A Purpose of this study is to examine the impact of organizational downsizing and discrimination activities on corporate social responsibility as measure by a company's reputation index. 
TABLE OF CONTENTS

$\underline{\text { Page }}$

ABSTRACT -----

TABLE OF CONTENTS ----------------------------------------------------- 3

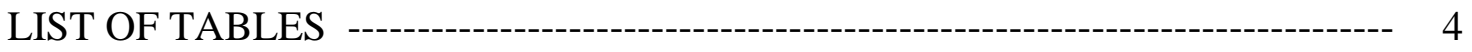

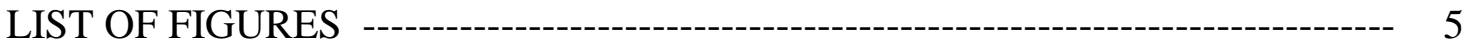

INTRODUCTION ---

Statement of the Problem -

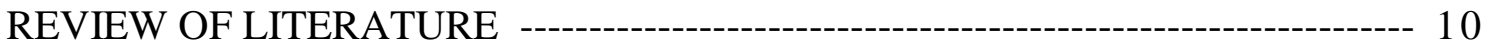

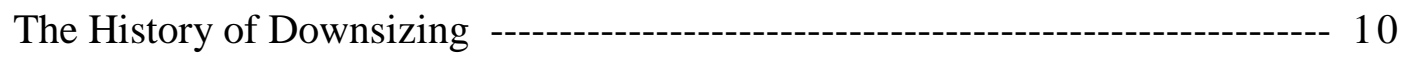

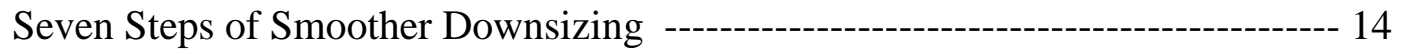

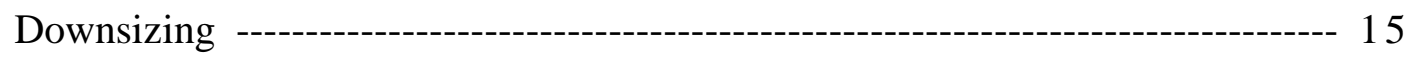

Downsizing versus Downscoping --------------------------------------------- 17

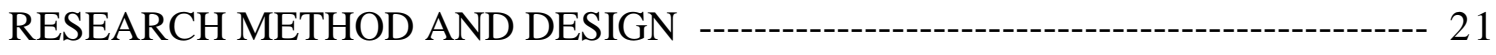

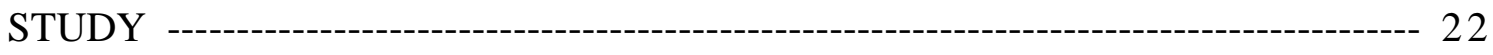

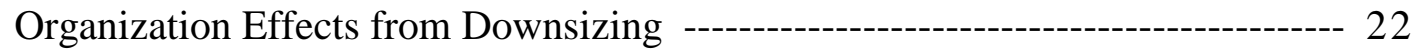

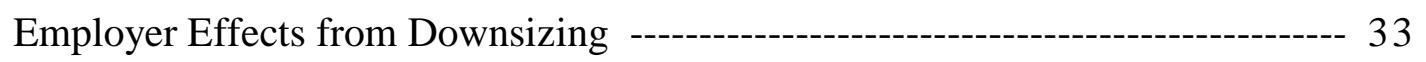

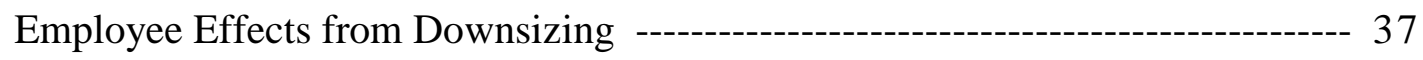

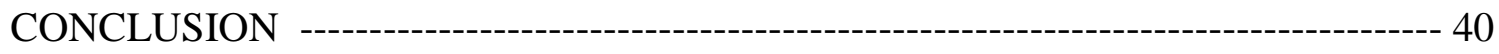

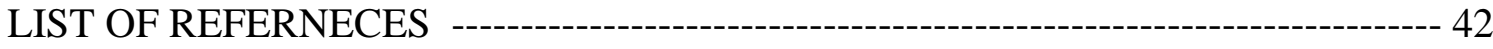

LIST OF TABLES 
$\underline{\text { Page }}$

1. Trend is Downsizing ---_on 11

2. Occupational Distribution of Downsizing - -

3. Comparison of Downscoping and Downsizing -------------------- 20

4. After-Effect of Downsizing ---

5. Manager's Satisfaction with Downsizing ----------------------------- 23 
1.Decomposition of Manufacturing Productivity

Growth (1977 -1987)

2. Support for Terminated Employees and Opportunities for

Employees to Have Questions Answered

3. Training of Supervisions in How to Motivate Remaining Employees and Training of Employees in How to Manage Transition

4. Explaining of The Reasons for The Downsizing

5. Communication About Future Mission of Organization and Explaining of Criteria Used to Decide Who was Terminated

6. Help in How to Deal with Increased Work Load

7. Pervasive Sense of Job Insecurity and Confidence in Future of Organization 30

8. Employee Productivity and Employee Resistance to Ongoing Change 31

9. Employee Passivity to Career Development and Retention of Top Talent 32

10. Employee Turnover

11. Opened up Communication with Employees and Rewarded Employees for Improved Profitability

12. Recognized Employees for Innovation and Initiative and Used Company Events to Rebuild Morale 35

13. Introduced Employee Development Program/Activities and Kept Organization Streamlined 36

14. Trust in Management, Productivity, Morale, Teamwork 
and Ability to Cope with Stress------------------------------------------------------ 38 


\section{Chapter 1}

\section{Research Opportunity and Objective}

\section{Introduction}

Organizational downsizing has been a pervasive phenomenon in the United States since the mid-1090s, with over $85 \%$ of the Fortune 1000 firms having engaged in some downsizing activity (Freeman \& Cameron, 1993; Hitt, Keats, Harback \& Nixon, 1994). Organizational downsizing has also been observed in other countries as increasing global competition and has led organizations to seek lower labor costs and increased productivity (Chao \& Kozlowski, 1994; Kozlowski, 1993). While organizational downsizing has become a common activity, it remains a phenomenon that has received relatively little theoretical or empirical attention (Cameron, 1994a). Cameron calls downsizing " probably the most pervasive yet understudied phenomenon in the business world" (1994a).

Though generally referring to an overall reduction in the size of a firm's work force, downsizing is a term that has come to have an almost generic meaning (Hitt et al., 1994). Accordingly, a wide range of actions, such as rightsizing, resizing, restructuring, delaying, and reengineering, have been addressed under the general rubric of downsizing. Regardless of the terminology used, however, the desire to be leaner, more flexible, and more responsive has made downsizing "the most pervasive form of organizational change" (Wiesenfeld, 1994) and a phenomenon deserving of future study.

However, many firms are reluctant to reveal information about their downsizing activities, citing current or potential legal actions or the desire to protect information from the scrutiny of competitors. Downsizing is clearly a sensitive topic, making the system study of downsizing particularly problematic. 


\section{Statement of the problem}

This paper will look at organizational downsizing.

\section{$\underline{\text { Research objective }}$}

The objectives of this study include:

1) A historical look at downsizing and some of its tools and technique;

2) The development and the implementation of downsizing activities;

3) Suggested recommendation for organizational improvement through downsizing activities.

\section{Limitation of the study}

The limitations of the study are:

1) The time available for the researcher

2) A single product package

3) Financial resources

4) A qualitative research

5) A statistical test is not available because a new body of knowledge is being created

6) Estimation of cost cannot be done 


\section{Chapter 2 \\ Literature of Review}

\section{The History of Downsizing}

Downsizing began as the strategy of sickly corporations shedding workers in the face of weak demand, but soon strong firms looking to boost shareholder value even further adopted the policy. Downsizing will be examined as a strategic option that management can exercise in order to boost equity value. Downsizing will be presented as a macro-economics phenomenon, having an impact on inflation, and therefore the rate at which stock prices are discounted and valued.

Since the early 1980s, job displacement has continued at many companies even in periods when there was sizable employment growth in the economy as a whole. For example, although from 1985 to 1989 total employment expanded by 11.7 million, during this period 4.3 million workers who had been with their employers for at least three years lost their jobs because their plants or businesses closed down or moved, their position or shifts were abolished, or not enough work was available for them to do (Herz, 1991). Roughly one in five workers saw his or her job disappear permanently during the 1980's. The rate of job loss among older and more educated workers was actually higher in 19901991 than it was in the depths of the recession of 1982-1983.

The data from the American Management Association (AMA) survey reported in Table 2.1 reveal no let up in the pace or scale of downsizing, even in the midst of the strong national economic growth that occurred in 1993 and 1994 (the recession that started in 1989 ended in most industries by early 1993). The percentage of companies planning to downsize actually rose slightly in 1994. 
Downsizing displacement have been unusual in their breadth as well as in their depth. One reflection of the broadening of downsizing of downsizing is the fast that the industrial focus of job displacement spread after 1980 as job displacement increased markedly in the service and retail trades sectors, moving beyond their earlier concentration in manufacturing industries (Podgursky, 1992). At the same time, even in the face of this broadening, job displacement did remain disproportionately concentrated in manufacturing and goods-producing industries.

Another reflection of the broadening of downsizing was the movement along the occupational axis from an earlier heavy concentration on blue-collar managerial employees at companies such as General Motors, Kodak, IBM, Exxon, and Merrill Lynch illustrated this development. Salaried employees had held $64.2 \%$ of the jobs eliminated in 1993-1994, which is significantly larger than salaried employees' share (40\%) of all jobs (American Management Association, 1994). The figure in Table 2.2 document the recent increase in the share of job cuts borne by middle management, supervisor, and professional/technical employees.

Table 2.1. Trend is Downsizing

\begin{tabular}{|lcc|}
\hline & $1993-94$ & $1989-90$ \\
\hline Companies reporting any workforce reduction(\%)* & 47.3 & 35.7 \\
Average reduction of workforce(\%) & 10.2 & 10.9 \\
\hline
\end{tabular}

These figures include companies that experienced any elimination of jobs during the surveyed period and not necessarily a net reduction in their work force.

Source: American Management Association(1994) 
Table 2.2. Occupational Distribution of Downsizing

\begin{tabular}{|lcc|}
\hline Percentage of jobs elimination that were: & $1993-94$ & $1990-91$ \\
\hline Hourly & $37.6 \%$ & $55.8 \%$ \\
Supervisory & 25.5 & 13.8 \\
Middle Management & 18.5 & 17.2 \\
Professional/Technical & 18.2 & 13.2 \\
\hline
\end{tabular}

Source: American Management Association (1994)

Detailed statistical analysis documents that by the mid-1980's, manager were actually more vulnerable to displacement due to downsizing and plant closings than were lower-level employees after controlling for industry and individual characteristics (e.g., education, experience, race, and sex) (Cappelli, 1992). These contrasts with earlier periods when downsizing was relatively concentrated among blue-collar employees and is consistent with the data reported earlier showing the disproportionate job cutting borne by salaried employees in the 1990's.

Perhaps the most striking change in the pattern of displacement is that toward the end of the 1980's, job loss was actually higher among older and more educated workers (Farber, 1993). This is in contrast to the historical influence of seniority-based layoffs that concentrated job loss on the youngest, entry-level workers. The shift toward older and more educated workers is consistent with the restructuring arguments, suggesting that jobs are being cut in the top rungs of the corporate hierarchy. 
Why do corporations downsize so abruptly and discharge so many employees all at once? That might at first seem like a silly question, but it is justified by the fact that corporate growth, the opposite of downsizing, tends to occur in a very gradual manner. New employees are typically hired after deliberate screening in an incremental fashion. Why, then, do companies let go of thousands of employees with so little notice? One reason for the abrupt character of downsizing is the fact that corporate executives commonly turn to downsizing in an effort to respond to severe financial pressures and as a result of the need to show quick results. A slow reduction in force would not do the job. In addition, since there is often resistance to change, companies often wait until financial conditions deteriorate substantially before making large-scale layoffs. Furthermore, the fear that disgruntled employees will turn to equal employment opportunity or age discrimination suits to challenge layoffs, appears to lead organizations to carry out reduction in mass, which offer some defense for their actions, since it is more difficult to make a charge of discrimination stand when so many other people (and many others with similar demographic or personal attributes) are simultaneously being laid off. (Alan, 1997).

\section{Seven steps to smoother downsizing}

According to Jackie Greaner (CEO and president, of EnterChange Inc.), there are seven steps to take to make a reduction in force or downsizing go more smoothly. 
1) Develop a careful, systematic transition plan. The plan should include: your goals and objectives; programs and services you will provide to both departing and remaining employees; and thorough consideration of how the plan will be implemented and communicated within the organization. As part of this planning, an organization needs to ask: "What is our purpose in undertaking this effort? To reduce overhead? Cut expense? Improve productivity? Improve departmental responsiveness? Serve other agencies or departments better?"

2) Ensure that top managers understand the "visionary" role they must play. Top managers must spearhead the downsizing plan if it is to be successful. They must explain clearly where the organization is going and provide support to middle-level managers who may have hands-on responsibility for implementing the plan.

3) Involve your personnel or human resources department. Work closely with human resources professionals to develop action plans and communication strategies.

4) Plan a communication strategy. How do you plan to "roll out" your downsizing plans? Will you downsize incrementally, or all at once? Be careful about boxing yourself in with a one-time action.

5) Communicate as much as you can, as soon as you can. Although you may be afraid of "overcommunicating" with employees, you need to keep in touch as RIF plans progress to create a climate of trust and to squelch the rumor mill that can imperil your plans.

6) Remember that you are changing the rules. RIFs or downsizing fundamentally change the operating assumptions and organizational realities by which everybody in the organization has always thought about his or her job, career, peers and 
relationship with the organization itself. Career transition and re-employment workshops for departing employees are critical, as are team-building and change-management programs for those who remain. Indeed, extra will be needed to forge common work values and organizational goals in the new environment.

7) Communicate tough decision in a human way. Talk about people and how the organization wants to help them make successful transitions to what comes next.

\section{Downsizing}

1) Ways of downsizing

* Across the board cutbacks

* Early retirement and voluntary severance

* De-layering

* Contract out specialized functions

* Drop the product lines

\section{2) Across the board cuts}

* Advantage

-- Pain is shared across organization

* Disadvantages

-- Efficient parts of the organization are hurt

-- Lack of a strategic plan

-- Little opportunity for transfers

\section{3) Early retirement and voluntary severance}

* Advantages

-- Concentrates job loss on the willing 
-- Higher paid long service employees likely to leave

* Disadvantages

-- Competent (with other opportunities) most likely to leave

-- Concentrated losses

-- Lack of strategic plan

-- Loss of corporate memory

4) De-layering: This is coupled with either more centralization or more

\section{delegation}

* Advantages

-- Pain is shared across all departments

-- Possibility of locating decision making at appropriate level

* Disadvantages

-- Organization memory lost

-- Top management may become overloaded

-- Costs of retraining

-- Cost of transition

\section{5) Contracting out functions}

* Advantage

-- Easy and immediate cost savings

* Disadvantages

-- Potential long term cost increases; suppliers engage in opportunism

-- Cost of coordinating a larger number of subcontractors

-- Time to train sub-contractors to your standards 
-- Lack of control over sub-contractors

\section{6) Dropping product lines}

* Advantages

-- Close connection with the strategic planning of the firm

-- Concentration of disruptions in a few business units

* Disadvantages

-- Potential for unanticipated business losses

-- Only a few people carry the burden

\section{7) Alternative to downsizing}

* Share the cuts across the organization. Rather than firing $10 \%$ of workforce, all members of the organization can take a $10 \%$ cut in both hours of work and pay. Perhaps surprisingly, this is the alternative for which employees often vote(Coral, 1996).

\section{Downscaling versus Downscoping}

A first step in deriving genera of downsizing strategies is to recognize that the reasons for downsizing can be placed in either of two basic groups, adaptive responses or strategic responses to environmental pressures or changes. Adaptive responses suggest fine-tuning changes and adjustments in the scale of an organization's activities. The emphasis is on improving or restoring performance and/or competitiveness through doing things differently while maintaining the same scope of business. Adaptive responses to environmental pressures can be provoked by:

Eroding market share;

1. International competition;

2. Rising labor cost; 
3. Economic contractions;

4. Change in customer's preferences;

5. Political changes; or

6. Development of new technologies or products that make current technologies or product obsoletes.

Strategic responses suggest more fundamental change and adjustment in the scope of an organization's activities. Strategic responses focus on doing different things rather than doing things differently. Strategic responses can be triggered by such changes as:

1. New goals;

2. Renewed focus on core business or strategy

3. Shifting to a new core business;

4. Opportunities to enter new product markets created by new technologies or actions of other firms;

5. Acquisitions or mergers; or

6. Divestitures

Viewing downsizing as either strategic or adaptive allows downsizing strategies to be grouped as those directed toward a reduction in the scope of an organization's activities and directed toward a reduction in the scale of an organization's activities. Implementing strategies to reduce the scope of a firm's activities is known as downsizing (Hoskisson \& Hitt, 1994) while implementing strategies to reduce the scale of an organization's activities, by extension, can be referred to as downsizing. 
Downscoping is intended to correct problems associated with over-diversification (e.g., increased managerial risk aversion) that inhibit innovation and competitiveness (Hoskisson \& Hitt, 1994) or with the use of inappropriate strategic controls. Downscoping may be formally defined as the implementation of strategies intended to reduce the scope of an organization's strategic controls. This can be accomplished through divestitures that permit the organization of divestitures and acquisitions that move the firm from a related-linked diversification strategy to either a related-constrained (increased reliance on strategic controls) or an unrelated (increased reliance on financial controls) diversification strategy (Hoskisson \& Johnson, 1992).

Similarly, downscaling is intended to correct problems associated with the overaccumulation of slack resources (Bourgeois, 1981) that may contribute to inefficiency and low productivity and, therefore, to higher costs and decreased competitiveness. Downsizing may be formally defined as the implementation of strategies intended to reduce the scale of an organization's activities, centering on a reduction in the level of the organization's slack resources. The relationship between downscoping and downscaling is summarized in Table 2.3. 


\section{Table 2.3. Comparison of Downscoping and Downsizing}

\begin{tabular}{|l|l|}
\hline $\begin{array}{l}\text { Downscoping } \\
\text { Purpose: }\end{array}$ & $\begin{array}{l}\text { Downscaling } \\
\text { Purpose: }\end{array}$ \\
Correct problems associated with over- & Correct problems associated with excess \\
diversification that inhibit innovativeness & slack resources that lead to inefficiency and \\
and reduce competitiveness. & low productivity \\
Focus: & Focus: \\
Reducing the number of businesses or & Eliminating redundancy and excess \\
product service offerings. & capacity. \\
Implementation: & Implementation: \\
Corporate level & Business and functional levels. \\
\hline
\end{tabular}

Source: Presented at the Annual Meeting of the Southwest Academy of Management, 1997 


\section{Chapter 3}

Research Methods and Research Design

This section describes the research method and research design used to develop and analysis a support package.

Qualitative Methods

In selecting research design an evaluation of qualitative and quantitative methods was performed. Essentially since quantitative research methods compares research results with existing body of knowledge, and since that kind of information was not available for the researcher due to the nature of the research statement, no quantitative methods could be applied.

Qualitative methodology study provides depth and detail through direct quotation and careful scrutiny of program situations, events, people interaction and observe behavior (Bogaden, 1975 \& Patton, 1987).

Qualitative research is exploratory one and open-ended.

\section{$\underline{\text { Research design }}$}

The research design employed qualitative methodology and various qualitative development tools. It is based upon developing a flexible model for a quality support package based on a downsizing and layoff environment and demonstrating the concept by applying the model to an existing product as an example for creating a organizational downsizing support package on various standards. The applied model will enable the researcher to then describe the process of creating an organizational downsizing support package. 


\section{Chapter 4}

\section{Study}

\section{Organization effect from downsizing}

The goal of downsizing program is to improve the performance of the organization, but does it really do so? The anecdotal evidence suggests a mixed picture. A Society of Human Resource Management survey of downsized companies found that $50 \%$ of the company respondents reported that productivity was either unchanged or dropped after downsizing. As reported in Table 4.1, less than majority of middle managers believes that the aftereffects of downsizing include increase in profits.

Table 4.1. After-Effects of Downsizing

\begin{tabular}{|lccc|}
\hline & Declined & Constant & Increased \\
\hline Operating profits* & $20 \%$ & $29 \%$ & $51 \%$ \\
Worker productivity & 30 & 36 & 34 \\
Employee morale & 86 & 12 & 2 \\
\hline
\end{tabular}

These figure were reported by 713 human resource managers in relatively large companies that experienced one or more spells of downsizing between 1989 and 1994. Source : American Management Association(1994)

The conventional wisdom claims that the rapid productivity growth experienced in the manufacturing sector in the United States has been caused in large part by the employment declines associated with corporate downsizing. However, recent analysis of company-level data shows that "there are in fact many manufacturing establishments 
where productivity growth accompanies increase in employment. Overall, plants that added workers contributed about the same to aggregate productivity as plants that downsized" (Baily, Bartelaman, and Haltivanger, 1994).

Many downsizing research also demonstrates that in many cases downsizing bring unanticipated harmful consequences to service quality and costs (Cascio, 1993). For one thing, the high performers that management wants to keep sometimes take advantage of early retirement or other severance options, and management ends up after downsizing with the wrong people.

\section{Table 4.2. Managers' Satisfaction with Downsizing}

Survey Question: Overall, how satisfied are you with the results of the downsizing?

Very satisfied(fully met corporate objectives)

Somewhat satisfied(met corporate objectives to some degree

with some negative results)

Minimally satisfied

Not satisfied at all

Not sure*

Another $13.1 \%$ of response to this question were missing.

Source: Louis Harris and Associates (1991), question B8.

Management's recent efforts to promote high-performance work teams may be harmed by downsizing. Managers and unionists often complain that layoffs (and associated seniority-based bumping) were extremely detrimental to the operation of work groups and teams. The harmful effect of downsizing on teams illustrates the tension that 
exists between strategies that promote internal flexibility and those that promote external flexibility. Many companies try to mix these strategies, and that does not work well.

A study done at the Bureau of the Census on productivity growth in manufacturing highlights the fact that downsizing may improve performance in some establishments but not in others (see Figure 4.1). The study labeled plants according to whether they were successful at "upsizing" (increasing both employment and productivity) or not (increasing employment while productivity fell) and whether they were successful “ downsizer" (productivity grew while employment shrank) or not (productivity fell while employment shrank). It found that the plants that were adding workers contributed about as much to overall productivity growth as did those that were cutting jobs.

Figure 4.1. Decomposition of Manufacturing Productivity Growth (1977-1987)

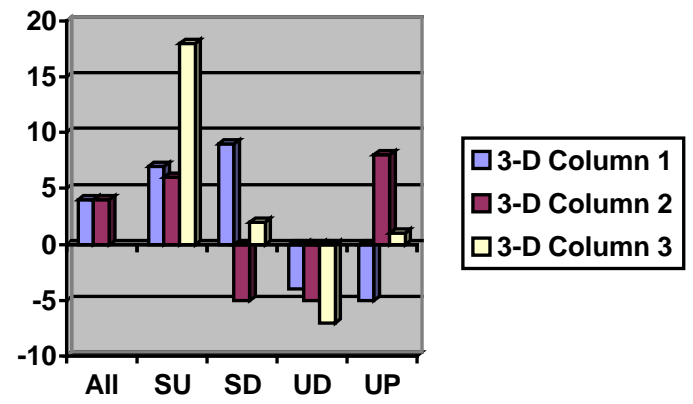

\section{Annual growth rates}

SU: Successful Upsizer

SD: Successful Downsizer

UD: Unsuccessful Downsizer

UP: Unsuccessful Upsizer
Column1: Labor.Prod. Growth

Column2: Employment Growth

Column3: Value-added Growth

Source: Adapted from Baily, Bartleman, and Haltiwanger (May 1994) 
While downsizing does not appear to work magic in all organizations, it clearly has been critical to the survival of some. It is hard to imagine that either IBM or General Motors, for example, would have been also to avoid bankruptcy without a heavy does of downsizing, although that does not imply that downsizing was accomplished in the most effective manner in those companies. And for nearly all U.S. business, it seems clear that the heightened economic competition and volatility requires that corporations find a way to become "lean and flexible."

\section{Employer effect form downsizing}

\section{Organizational response}

There are many immediate steps that organizations can take in the wake of a downsizing to help remaining employees adjust to the change. As can be seen from Figure 4.2, some actions are more universally successful than others, but all had a positive effect in more than half of the organizations that implemented them.

To Improve trust in Management

$\rightarrow$ Make senior management visible

$\rightarrow$ Explain reason for the downsizing

$\rightarrow$ Explain criteria used to decide who was terminated 
Figure 4.2. Support for terminated employees and Opportunities for employees to have questions answered

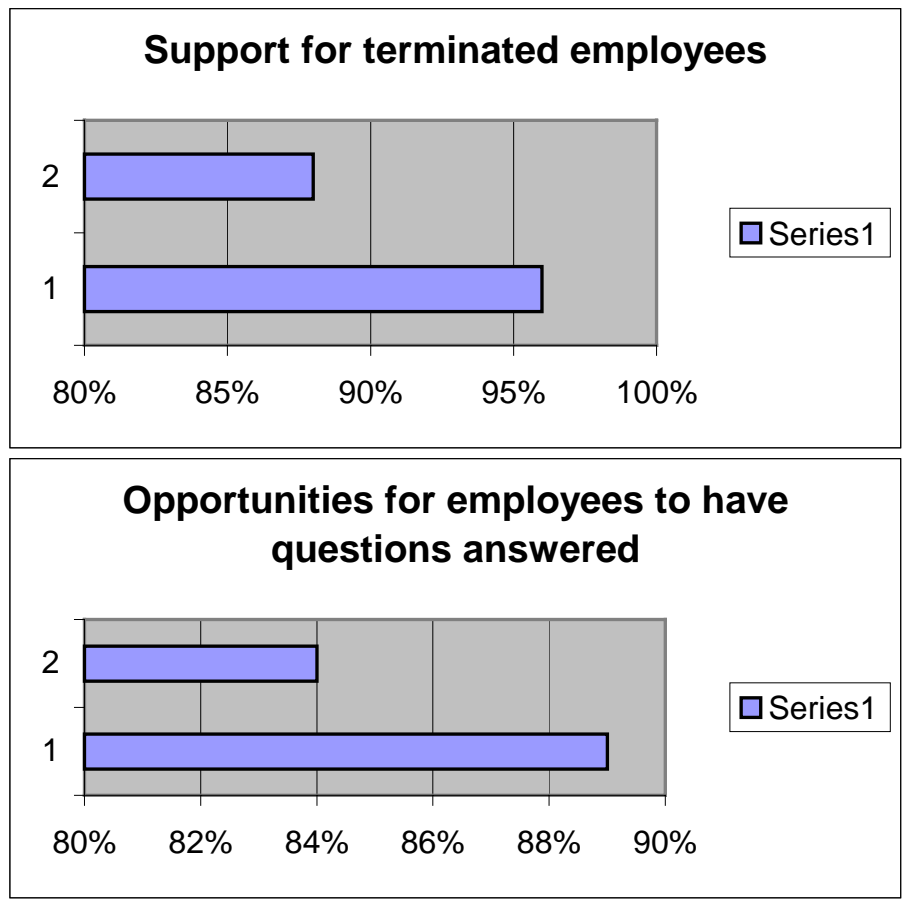

1: Took action

2: Repotted positive effect

Source: Hyundai group research Association(1997)

\section{To Improve morale}

$\rightarrow$ Provide many opportunities for employees to have questions answered

$\rightarrow$ Communicate - as specifically as possible - future mission of the organization

$\rightarrow$ Let survivors know how terminated employees are being supported 
Figure 4.3. Training of supervisions in how to motivate remaining employees and Training of employees in how to manage transition
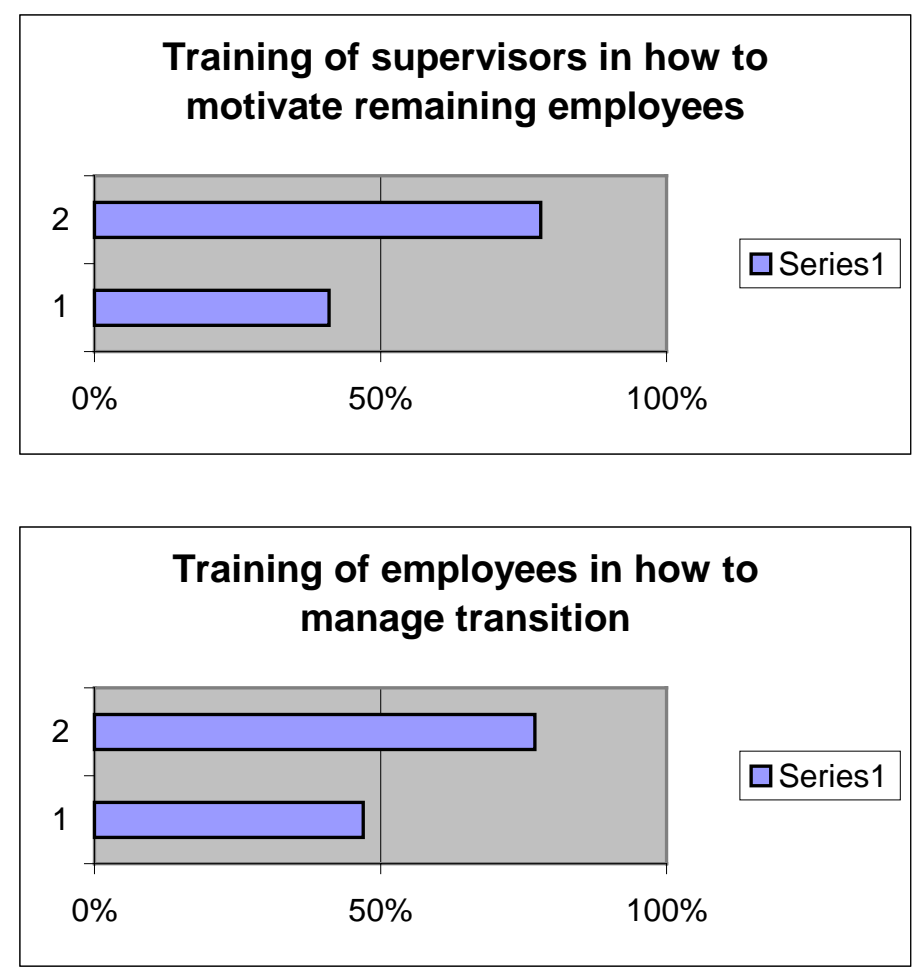

1: Took action

2: Reported positive effect

Source: Hyundai Group Research Association(1997)

\section{To Improve Productivity}

$\rightarrow$ Train supervisors in how to motivate and manage survivors

$\rightarrow$ Help survivor determine how to handle increased work load 
Figure 4.4. Explaining of the reasons for the downsizing
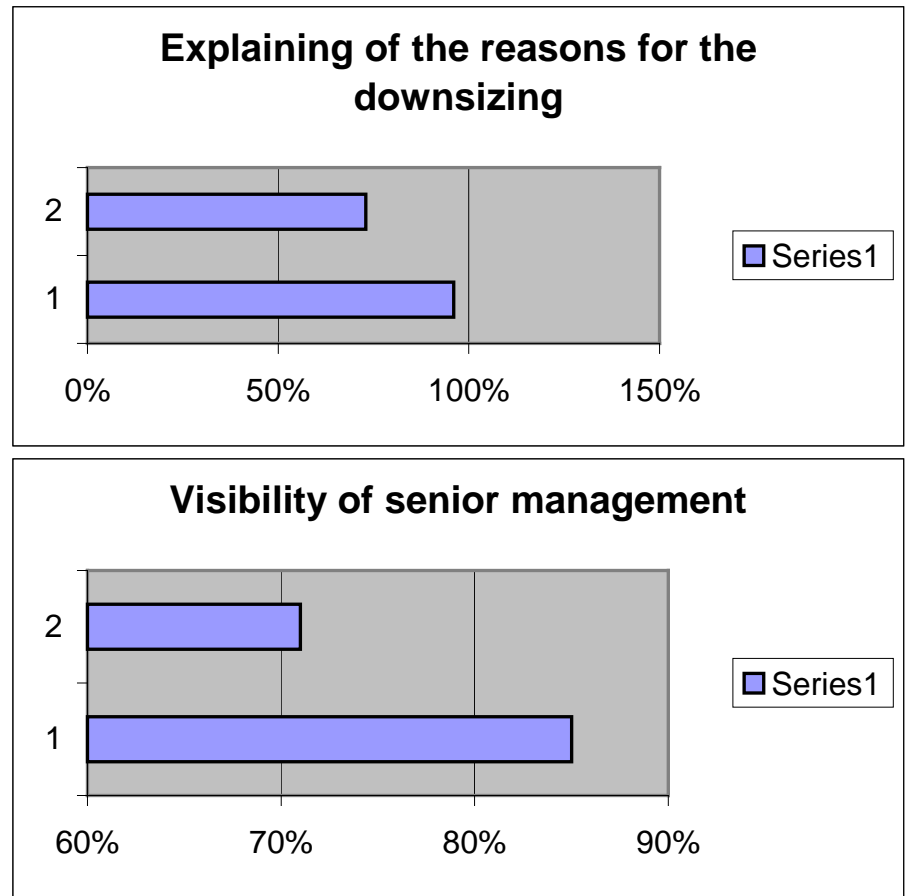

1: Took action

2: Reported positive effect

Source: Hyundai Group Research Association(1997)

To Improve Stress Levels

$\rightarrow$ Train survivors in how to manage change and transition 
Figure 4.5. Communication about future mission of organization and Explaining of criteria used to decide who was terminated
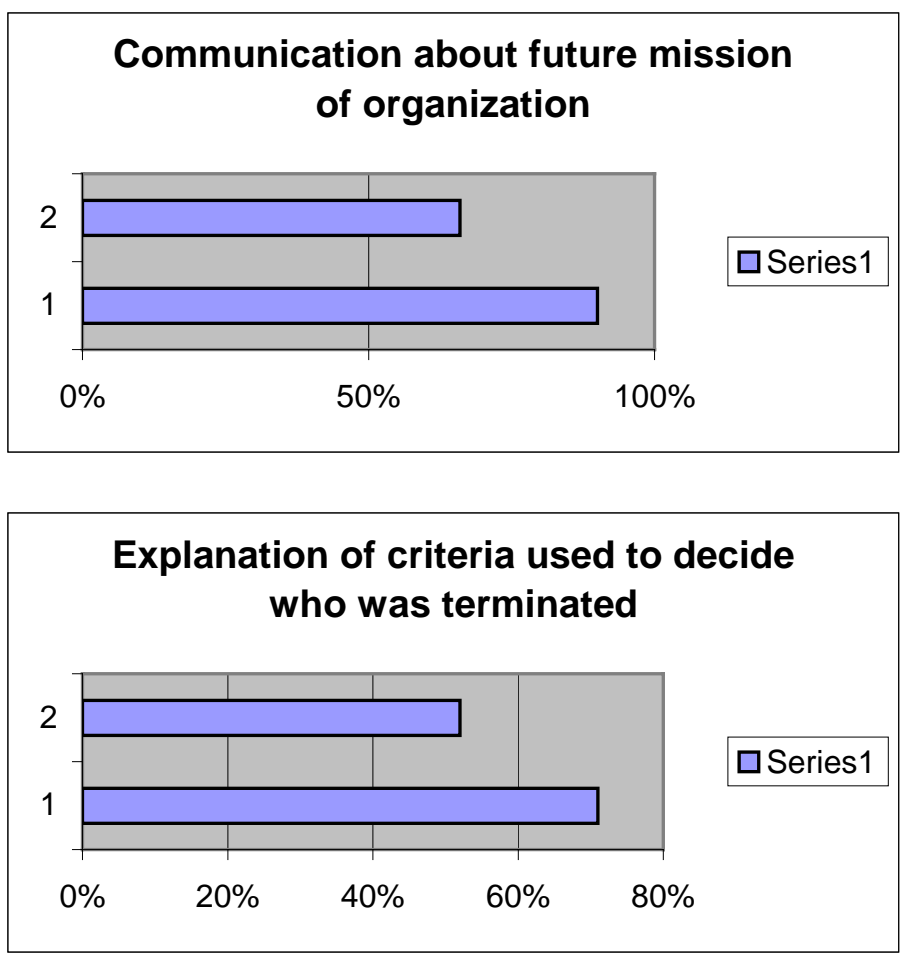

1: Took action

2: Reported positive effect

Source: Hyundai Group Research Association(1997)

To Improve Teamwork

$\rightarrow$ Help survivors determine how to handle increased work load 
Figure 4.6. Help in how to handle increased workload

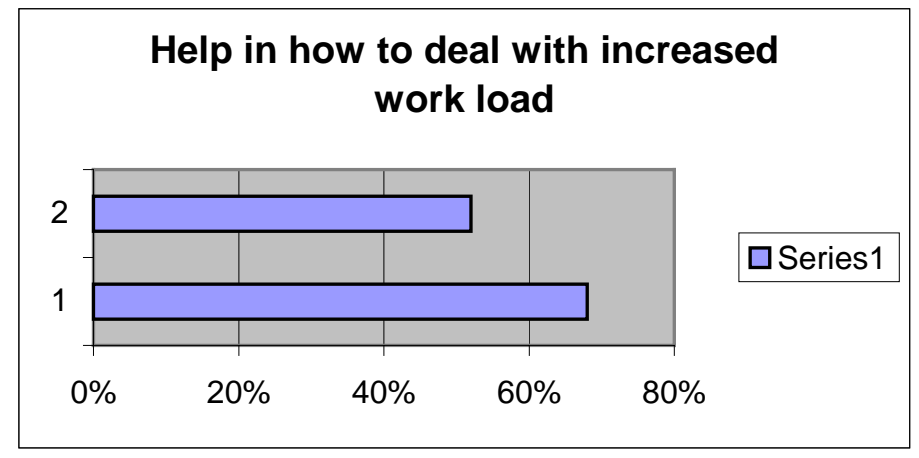

1: Took action

2: Reported positive effect

Source: Hyundai Group Research Association(1997)

Organizational Long-Term Action and Short-Term Action

\section{Job Insecurity}

$\rightarrow$ Short-term Actions: Make senior management visible. Explain reasons for the downsizing. Communicate future mission of the organization.

$\rightarrow$ Long-term Action: Open up communications with employees. Keep organization streamlined. Use company events to rebuild morale.

Figure 4.7. Pervasive sense of job insecurity and confidence in future of organization

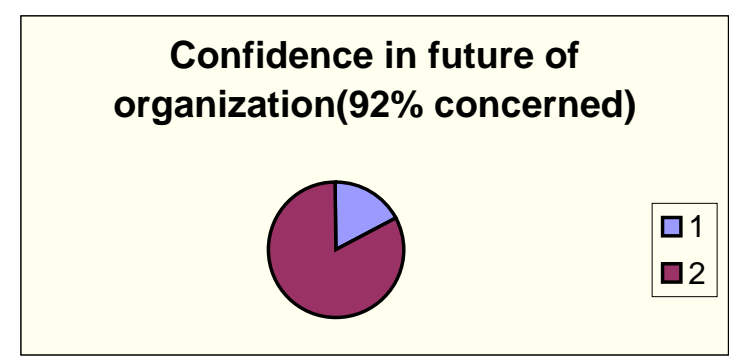




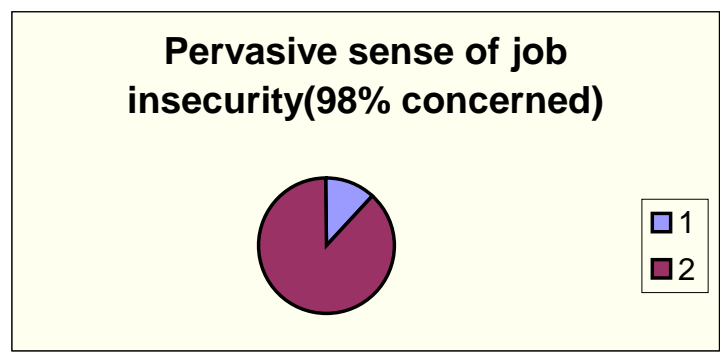

\section{1:Minor concern}

2:Major concern

Source: Lee Hecht Harrison(1994)

\section{Confidence in future organization}

$\rightarrow$ Short-term Actions: Make senior management visible. Communicate future mission of the organization. Train supervisors and employees in change management. Explain reasons for the downsizing and criteria for termination.

$\rightarrow$ Long-term Actions: Keep organization streamlined. Recognize employees for innovation and initiative.

Figure 4.8. Employee productivity and Employee resistance to ongoing change

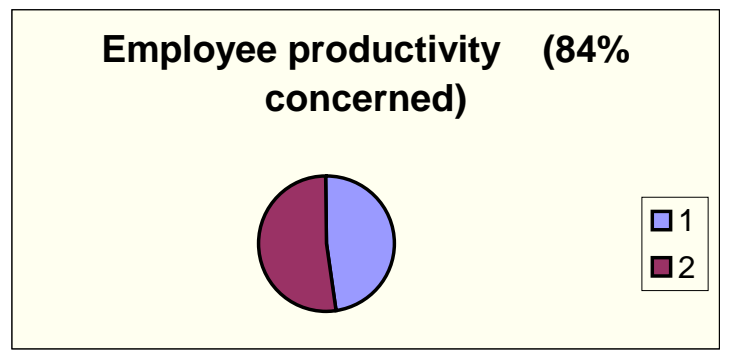




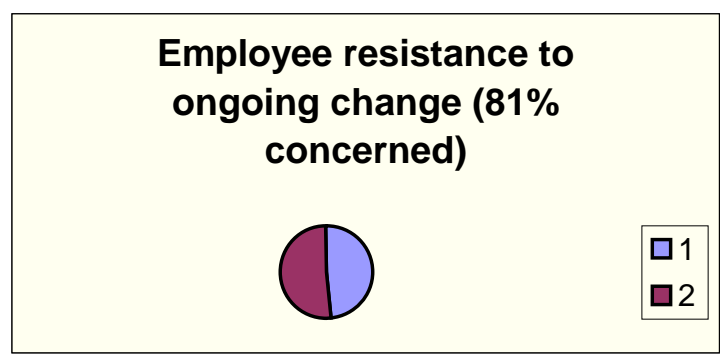

1: Minor concern

2: Major concern

Source: Lee Hecht Harrison (1994)

\section{Employee Productivity}

$\rightarrow$ Short-term Actions: Train supervisors in how to survivors.

$\rightarrow$ Long-term Actions: Reward employees for improved profitability.

Figure 4.9. Employee passivity to career development and Retention of top talent
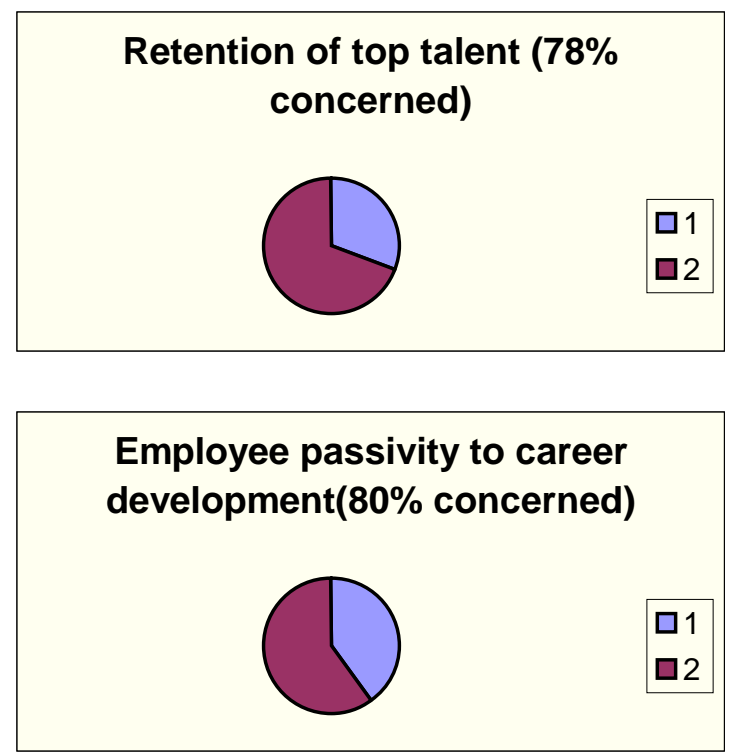

1: Minor concern

2: Major concern

Source: Lee Hecht Harrison(1994) 


\section{Employee Resistance to Change}

$\rightarrow$ Short-term Actions: Train supervisors and employees in change management. Explain reasons for the downsizing.

$\rightarrow$ Long-term Actions: Recognize employees for innovation and initiative. Open up communications with employees.

$\underline{\text { Figure 4.10 Employee turnover }}$

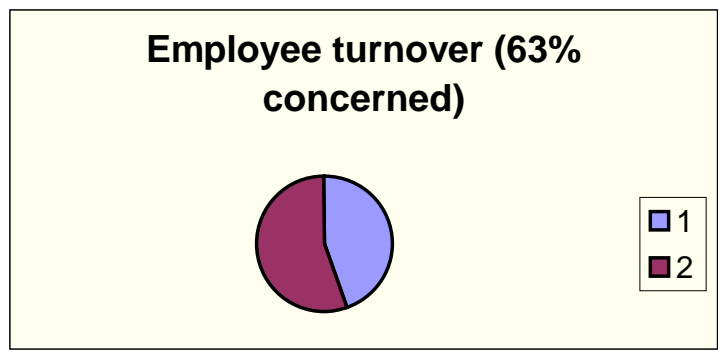

1: Minor concern

2:Major concern

Source: Lee Hecht Harrison(1994)

\section{Employee Passivity Regarding Career Development}

$\rightarrow$ Short-term Actions: Make senior management visible. Support terminated employees. Explain reasons for the downsizing.

$\rightarrow$ Long-term Actions: Introduce employee development program/activities. Explain reasons for the downsizing. 
Figure 4.11. Opened up communication with employees and rewarded employees for improved profitability
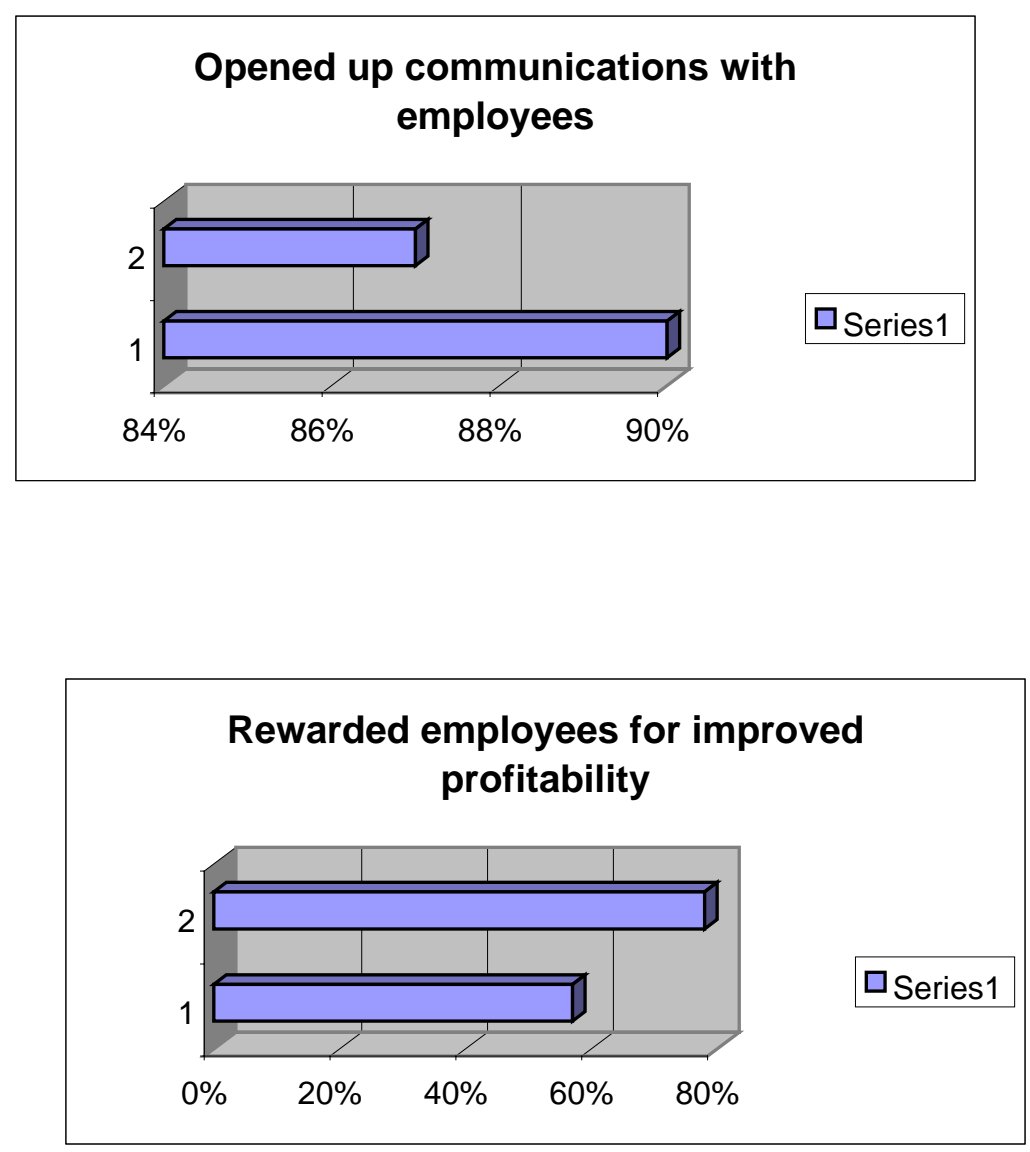

1: Took action

2: Reported positive effect

Source: Hyundai Group Research Association(1997)

\section{Retention of Top Talent}

$\rightarrow$ Short-term Actions: Communicate the future mission of the organization.

$\rightarrow$ Long-term Actions: Recognize employees for innovation and initiative. 
Figure 4.12. Recognized employees for innovation and initiative and used company events to rebuild morale
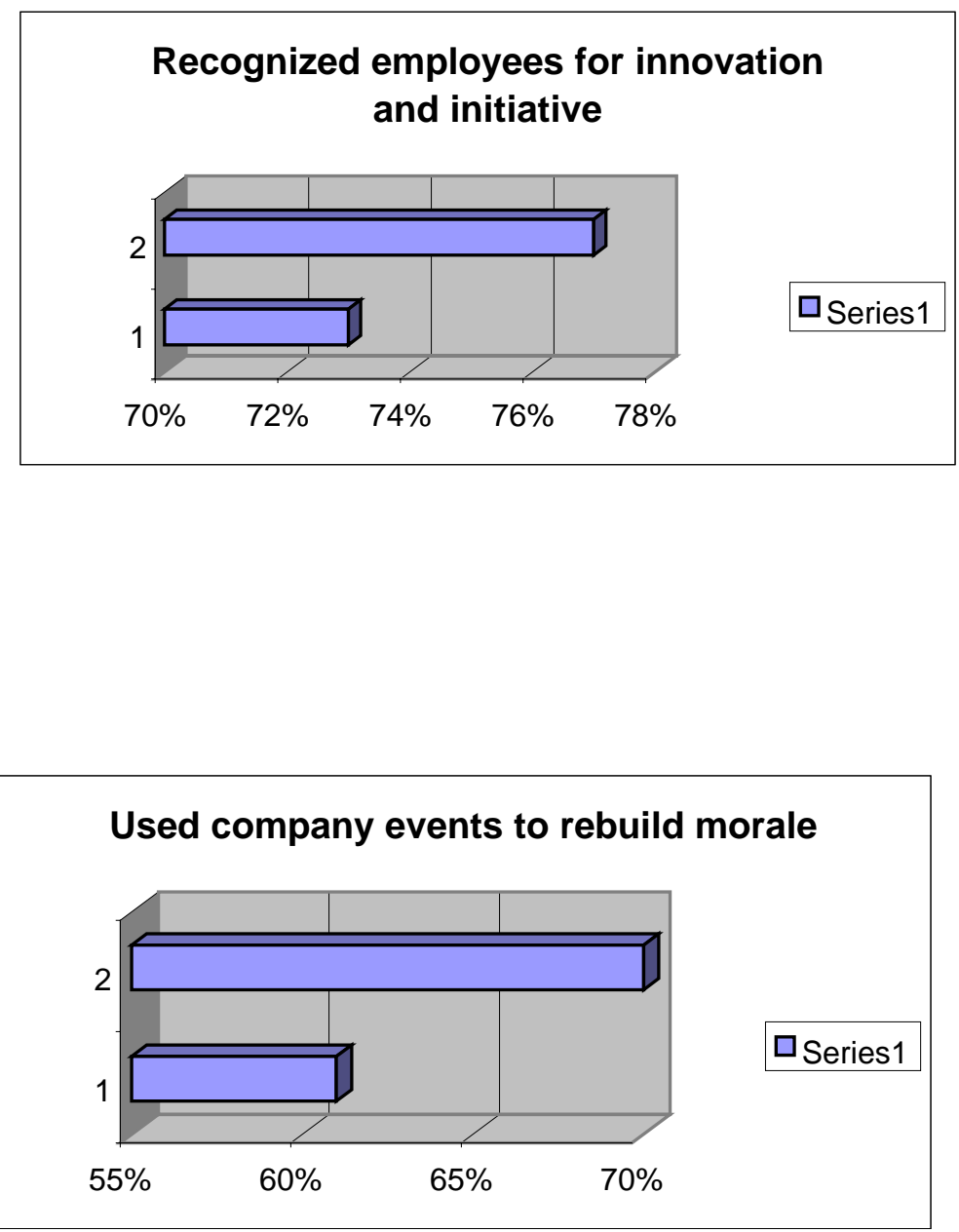

1: Took action

2: Reported positive effect

Source: Hyundai Group Research Association(1997)

\section{Employee Turnover}

$\rightarrow$ Short-term Actions: Help survivors determine how to handle increased work load. Train supervisors and employees in change management.

$\rightarrow$ Long-term Action: Reward profitability. Use company events to rebuild morale. 
Figure 4.13. Introduced employee development program/activities and Kept organization streamlined
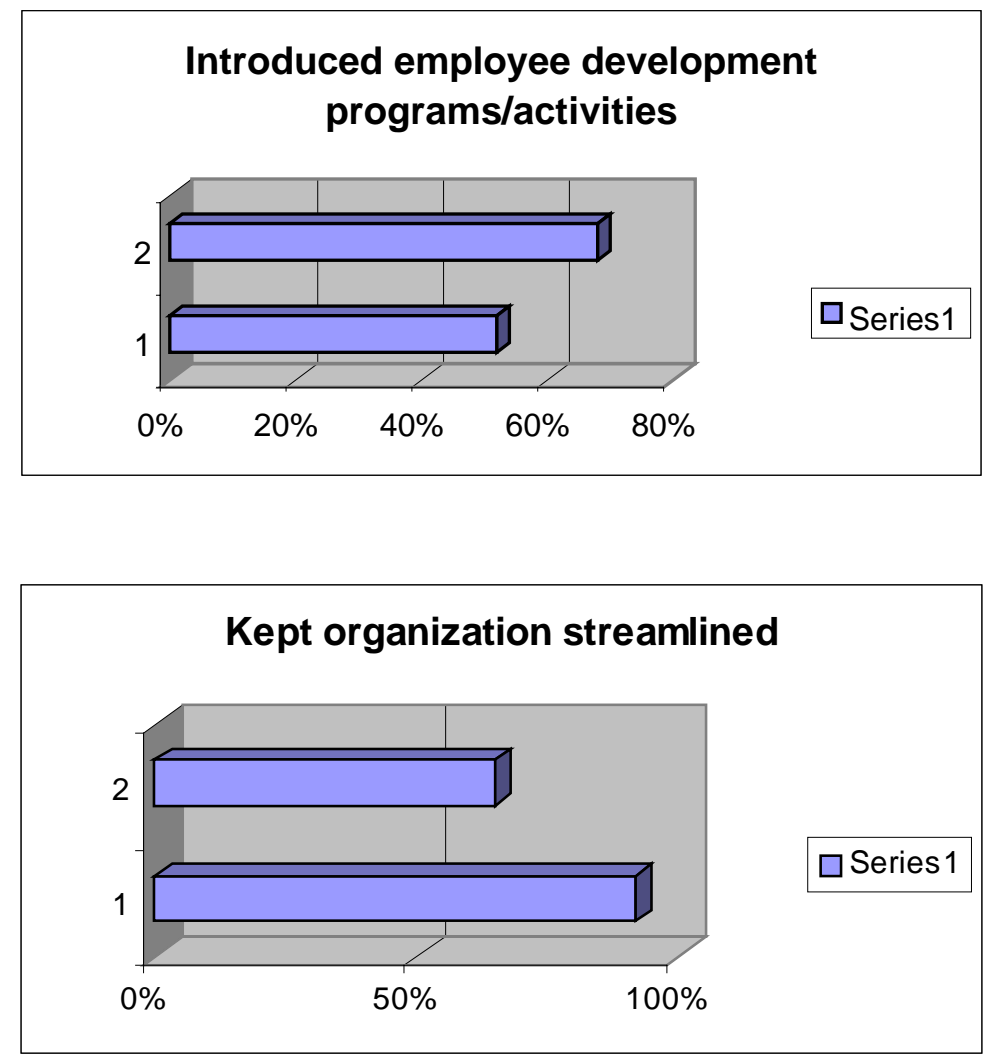

1: Took action

2: Reported positive effects

Source: Hyundai Group Research Association(1997) 


\section{Employee effect from downsizing}

While employers appear to be generally satisfied with the outcomes produced by downsizing, employees are quite disturbed by these events. Employer satisfaction with downsizing is evident as well as in the frequency with which companies have adapted downsizing. In the Harris survey data reported in Table 4.2, for example, $79 \%$ of management respondents reported that they were either "very" or "somewhat" satisfied with the downsizing that had occurred in their organizations, while only $1 \%$ were not satisfied.

The harmful effects of downsizing on the income of laid-off employees is clear from the evidence discussed earlier. Perhaps as troubling is the evidence that has surfaced in recent years showing that downsizing also brings severe morale problems among retained employees after a downsizing.

The organizational behavior literature has created a new term, "survivors syndrome," to refer to morale problems among those who remain in the downsized organization. Survivors are also affected by how their work conditions and work environment are altered by downsizing. A review of studies of survivor's reactions finds that " the postlayoff environment has the potential to be quite stressful for a variety of reasons (e.g., survivors' concerns about job insecurity). Stress, in turn, has the potential to affect adversely survivors' work attitudes and behaviors" (Brockner, 1998). Some individuals are driven to work harder after surviving a layoff, particularly those with low self-esteem who become worried about their own job security after watching layoffs.

In addition, downsizing can create job demands that employees are not prepared for or equipped to handle. "A common complaint among top managers was that downsizing created job demands that most of their managers were not qualified to fulfill" 
(Cameron, Freeman, \& Mashra, 1993). Employees were asked, in the face of downsizing, to take on broader and unfamiliar responsibilities as part of efforts to cover the tasks previously performed by those who were let go. Because of such demands, burnout, frustration, and declines in organizational commitment follow many corporate downsizing.

Figure 4.14. Trust in management, productivity, morale, teamwork and ability to cope with stress
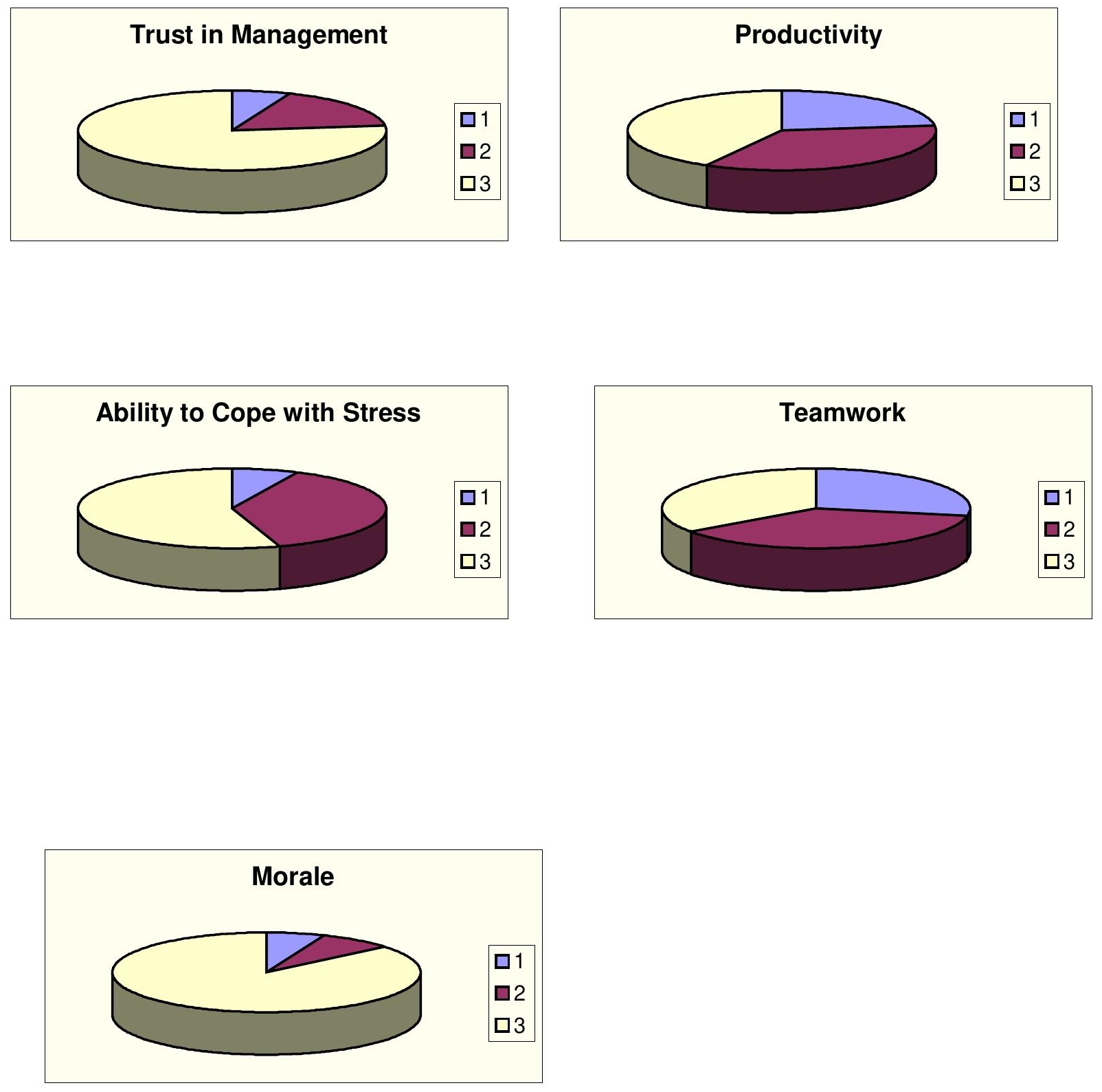
1: Higher than before

2: Same as before

3: Lower than before

Source: Lee Hecht Harrison (1994)

\section{Chapter 5}

\section{Conclusion}

The depth and breath of downsizing in recent years has been alarming. Employees of all occupational groups and economic sectors continue to fear that they may be next on 
the downsizing list. These fact that there is no letup in sight in the pace of corporate downsizing.

When they downsize, corporations often try to ameliorate the harmful effects on both the laid off and the retained. Yet, even in the face of these efforts, downsized employees suffer substantial income losses, and for those who remain on the payroll, work often intensifies and morale plummets in the face of heightened insecurities.

In addition to this obvious dark side, downsizing has other costs as well. Corporate profits and employee productivity do not improve in many companies that travel the downsizing path. But for some companies, downsizing has been essential to their survival and has become an integral part of their renewal process.

Whether downsizing works well depends on the extent to which it is associated with wide and deep corporate and work reorganization. Corporate strategy, here as elsewhere in the U.S. economy, is a critical driving force. For some companies, downsizing is an end in itself, while other companies effectively mesh downsizing with internal reorganization.

U.S. corporations would be well advised to make greater use of the latter approach so as to increase the use of internal transfers and retraining and thereby lessen the frequency and scale of downsizing. As discussed in this and other chapter of this paper, the effective use of these alternatives to downsizing can yield substantial long-term payouts and lessen the employee resentment and fears generated by downsizing. Yet, the evidence suggests that there is no one best way to reorganize, nor is it likely that the need for downsizing can be completely eliminated. 
The consequences of downsizing depend on how it is accomplished and on the other corporate decisions that go along with the act of downsizing. Most critical is the degree to which companies are able to convince their employees of the rationale for downsizing an involve employees in the decision-making process. 


\section{REFERENCE}

Berman,E., (1998, October). The victims of downsizing. Journal of Industrial Management, 40(5).

Sherrod, L., (1999, January). How to survive downsizing. Journal of Essence. $29(9), 62,2 / 5$.

Lanier, K. (1998, January). Life after downsizing. Journal of Christian Science Monitor, 91(38), 14.

Robbins, S. P. (1998,Feb). Layoff-survivor sickness. Journal of Management Education, 23(1), 31.

Doust, R. (1998, Dec). Downsizing: making it work. CA-Magazine, 131(10), 1620.

Miller, R. A. (1998, Nov). Lifesizing in an era of downsizing. Journal of Business Ethics, 17(15), 1693-1700.

Hoffman, G. ( 1998, September). Downsizing America. Progressive Grocer, 77(9), 136.

Mehay. S. L. (1998, July). The effect of separation bonuses on voluntary quits. Southern Economic Journal, 65(1), 127-39.

Jacoby. S. (1998, May). Downsizing in the past. Challenge, 41(3), 100-12.

Lambright. W. (1998, May). Downsizing big science. Public Administration Review, 58(3), 259-68.

Richards. G. (1998, March). Downsizing slows, space efficiency remains a virtue. National Real Estate Investor, 40(3), 66+. 
Johnson. B. (1998,Feb). IBM downsizing direct roster to four agencies. Advertising Age, $69,45$.

Mishra. K. E. (1997, Winter). Preserving employee morale during downsizing. Sloan Management Review, 29, 83-95.

Karake. Z. A. (1997, Summer). An examination of the impact of organizational downsizing and discrimination activities on corporate social responsibility as measured by a company's reputation index. Management Decision, 36(3), 206-16.

Lee. H. (1994, Summer). After Downsizing. Lee Hecht Harrison , 3-15.

Hyundai Group. (1997, Winter). Downsizing Results. Hyundai Group Research Association, 123-172.

Peter. C. (1997). Downsizing and Employment Insecurity. Change at work, 66-88. Cole. R. E. (1995). Downsizing, quality and performance. The death and life of the American Quality Movement, 93-114. 
